UMTRI-98-30

\title{
CONSPICUITY AND GLARE PROPERTIES OF DAYTIME RUNNING LIGHTS: EFFECTS OF LAMP SEPARATION AND INTENSITY
}

\author{
Michael Sivak \\ Michael J. Flannagan \\ Eric C. Traube \\ Toshio Miyokawa
}

August 1998 
CONSPICUITY AND GLARE PROPERTIES OF DAYTIME RUNNING LIGHTS: EFFECTS OF LAMP SEPARATION AND INTENSITY

Michael Sivak

Michael J. Flannagan

Eric C. Traube

Toshio Miyokawa

The University of Michigan

Transportation Research Institute

Ann Arbor, Michigan 48109-2150

U.S.A.

Report No. UMTRI-98-30

August 1998 


\begin{tabular}{|c|c|c|c|c|}
\hline 1. Report No. & 2. Government Accession No. & & $\begin{array}{l}\text { Technical Report } \\
\text { 3. Recipient's }\end{array}$ & $\begin{array}{l}\text { Documentation Pag } \\
\text { atalog No. }\end{array}$ \\
\hline UMTRI-98-30 & & & & \\
\hline $\begin{array}{l}\text { 4. Title and Subtitle } \\
\text { Conspicuity and Glare Prope }\end{array}$ & ies of Daytime Running & ights: & $\begin{array}{l}\text { 5. Report Date } \\
\text { August } 19\end{array}$ & \\
\hline Effects of Lamp Separation a & Intensity & & $\begin{array}{l}\text { 6. Performing O } \\
302753\end{array}$ & ganization Code \\
\hline $\begin{array}{l}\text { 7. Author(s) } \\
\text { Sivak, M., Flannagan, M.J., T }\end{array}$ & ube, E.C., and Miyokaw & & $\begin{array}{l}\text { 8. Performing C } \\
\text { UMTRI-9 }\end{array}$ & $\begin{array}{l}\text { rganization Report No. } \\
3-30\end{array}$ \\
\hline $\begin{array}{l}\text { 9. Performing Organization Name and Add } \\
\text { The University of Michigan }\end{array}$ & & & 10. Work Unit $n$ & o. (TRAIS) \\
\hline $\begin{array}{l}\text { Transportation Research Insti } \\
2901 \text { Baxter Road } \\
\text { Ann Arbor, Michigan 48109- }\end{array}$ & 150 U.S.A. & & 11. Contract or & Grant No. \\
\hline $\begin{array}{l}\text { 12. Sponsoring Agency Name and Addres } \\
\text { The University of Michigan }\end{array}$ & & & 13. Type of Re & ort and Period Covered \\
\hline $\begin{array}{l}\text { Industry Affiliation Program } \\
\text { Human Factors in Transporta }\end{array}$ & on Safety & & 14. Sponsoring & Agency Code \\
\hline $\begin{array}{l}\text { 15. Supplementary Notes } \\
\text { The Affiliation Program } \\
\text { International, Chrysler, Corn } \\
\text { GM NAO Safety Center, Hel } \\
\text { LESCOA, Libbey-Owens-I } \\
\text { Sylvania, Philips Lighting } \\
\text { TEXTRON Automotive, Vale } \\
\text { and 3M Traffic Control Mate } \\
\text { Information about the Affiliat }\end{array}$ & $\begin{array}{l}\text { Irrently includes Ada } \\
\text { g, Delphi Interior and I } \\
\text {, Hewlett-Packard, Ichil } \\
\text { rd, Magneti Marelli, } \\
\text { PPG Industries, Refle } \\
\text {, Visteon, Wagner Ligl } \\
\text { als. } \\
\text { on Program is available a }\end{array}$ & $\begin{array}{l}\text { Plas } \\
\text { ghtin } \\
\text { h Ind } \\
\text { orth } \\
\text { ite, } \\
\text { ng, } 3 \\
\text { http: }\end{array}$ & $\begin{array}{l}\text { ics, BMW, } \\
\text { Systems, D } \\
\text { istries, Koito } \\
\text { American L } \\
\text { tanley Elec } \\
\text { M Personal } \\
\text { /www.umich }\end{array}$ & $\begin{array}{l}\text { Bosch, Britax } \\
\text { enso, Ford, GE, } \\
\text { Manufacturing, } \\
\text { ghting, Osram } \\
\text { ric, Stimsonite, } \\
\text { Safety Products, } \\
\text { edu/ industry/ }\end{array}$ \\
\hline 16. Abstract & & & & \\
\hline $\begin{array}{l}\text { This study evaluated } \\
\text { effectiveness of daytime ru } \\
\text { discomfort glare from a pair } \\
\text { same nine stimuli were used i } \\
\text { nine stimuli were obtained } \\
\text { intensity directed towards th } \\
\text { cd), and three levels of lamp } \\
\text { was performed outdoors, on } \\
\text { As expected, lamp } \\
\text { conspicuity. On the other har } \\
\text { an effect on conspicuity ( } \\
\text { discomfort glare (a statisticall } \\
\text { slightly more discomforting) } \\
\text { narrowly separated lamps is c } \\
\text { benefit for narrowly separa } \\
\text { separated lamps that are as } n \\
\text { be less glaring. The presen } \\
\text { narrowly separated daytime }\end{array}$ & $\begin{array}{l}\text { e influences of lamp s } \\
\text { ing lights. Subjects } \\
\text { lamps, and evaluated th } \\
\text { both the glare and cons } \\
\text { the orthogonal comb } \\
\text { subject's eyes from the } \\
\text { aration ( } 1.05,0.65 \text {, and } \\
\text { ght, sunny days. The vi } \\
\text { ensity had strong eff } \\
\text { in the case of lamp sep } \\
\text { rowly separated lamp } \\
\text { nonsignificant trend for } \\
\text { Consequently, if the p } \\
\text { interacted by a slight ree } \\
\text { damps in terms of } \\
\text { iceable as widely separ } \\
\text { findings imply that th } \\
\text { ning lights. }\end{array}$ & $\begin{array}{l}\text { arati } \\
\text { rforn } \\
\text { onsp } \\
\text { uity } \\
\text { ation } \\
\text { vo la } \\
25 \\
\text { ving } \\
\text { s on } \\
\text { ation }\end{array}$ & $\begin{array}{l}\text { and lamp } \\
\text { ed two task } \\
\text { uity of the } s \\
\text { ortions of th } \\
\text { f three lev } \\
\text { ps }(14,000 \text {, } \\
\text { edge to ec } \\
\text { stance was } 2 \\
\text { both discor } \\
\text { here was m } \\
\text { more notic } \\
\text { separated l } \\
\text { ncrease in } \\
\text { n intensity, t } \\
\text { ity. Conv } \\
\text { os of higher } \\
\text { small net } 1\end{array}$ & $\begin{array}{l}\text { intensity on the } \\
\text { s. They rated } \\
\text { ame lamps. The } \\
\text { e study. These } \\
\text { els of luminous } \\
3,500 \text {, and } 875 \\
\text { ge). The study } \\
0 \text { m. } \\
\text { nfort glare and } \\
\text { ore evidence for } \\
\text { eable) than on } \\
\text { amps to be only } \\
\text { liscomfort from } \\
\text { eere is still a net } \\
\text { ersely, narrowly } \\
\text { intensity would } \\
\text { enefit in using }\end{array}$ \\
\hline $\begin{array}{l}\text { 17. Key Words } \\
\text { daytime running lights, headla } \\
\text { discomfort glare, luminous in }\end{array}$ & $\begin{array}{l}\text { ps, lamps, conspicuity, } \\
\text { sity, lamp separation }\end{array}$ & $\begin{array}{l}18.5 \\
\text { Unl }\end{array}$ & $\begin{array}{l}\text { stribution Statemer } \\
\text { mited }\end{array}$ & \\
\hline $\begin{array}{l}\text { 19. Security Classification (of this report) } \\
\text { None }\end{array}$ & $\begin{array}{l}\text { 20. Security Classification (of this } \\
\text { None }\end{array}$ & ge) & $\begin{array}{l}\text { 1. No. of Pages } \\
22\end{array}$ & 22. Price \\
\hline
\end{tabular}




\section{ACKNOWLEDGMENTS}

Appreciation is extended to the members of the University of Michigan Industry Affiliation Program for Human Factors in Transportation Safety for support of this research. The current members of the Program are:

Adac Plastics

BMW

Bosch

Britax International

Chrysler

Corning

Delphi Interior and Lighting Systems

Denso

Ford

GE

GM NAO Safety Center

Hella

Hewlett-Packard

Ichikoh Industries

Koito Manufacturing

LESCOA

Libbey-Owens-Ford

Magneti Marelli

North American Lighting

Osram Sylvania

Philips Lighting

PPG Industries

Reflexite

Stanley Electric

Stimsonite

TEXTRON Automotive

Valeo

Visteon

Wagner Lighting

3M Personal Safety Products

3M Traffic Control Materials 


\section{CONTENTS}

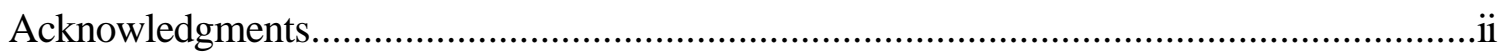

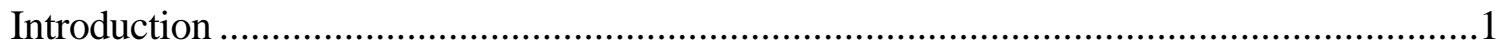

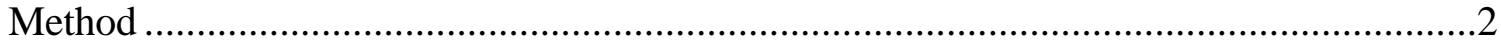

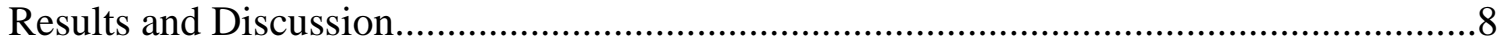

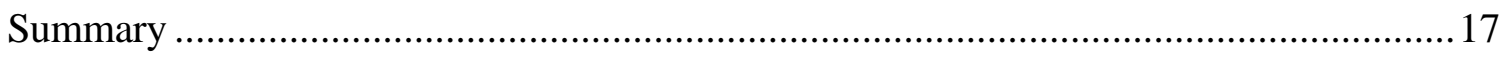

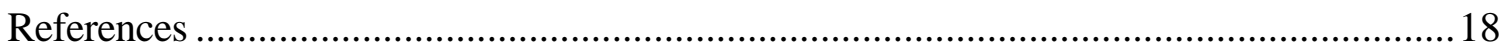




\section{INTRODUCTION}

The daytime conspicuity of motor vehicles was taken for granted during the first 60 years of motorization. The traditional point of view was well expressed by Allen and Clark (1964), when they pointed out that "It seems that no one can conceive of an automobile or a Greyhound Bus being invisible on a bright clear day!” (page 4). However, starting in the 1960s, the need for an improvement in the daytime conspicuity of vehicles-whether cars, trucks, buses, or motorcycles-became recognized. The usual solution has been the socalled daytime running lights (DRLs). DRLs involve using lighted lamps during the daytime. The DRL function has been embodied in various ways, including standard low beams, reduced-intensity low beams, reduced-intensity high beams, standard fog lamps, increased-intensity position lamps, dedicated lamps, etc. (CIE, 1993).

Currently, it is generally acknowledged that the use of DRLs has positive effects on daytime traffic safety (e.g., CIE, 1993; Elvik, 1996; Helmers, 1988; Koornstra, Bijleveld, and Hagenzeiker, 1997; but cf., Theeuwes and Riemersma, 1995). (However, there is some evidence that the effect increases with an increase in the latitude of the geographical region in question (e.g., Koornstra et al., 1997; Elvik, 1996). A possible mechanism for this effect is the increased length of twilight with increased latitude.)

Cost-benefit analyses have concluded either that there are major net benefits in using DRLs (Koornstra et al., 1997), or that the possible net outcomes include both benefits and disbenefits (Lawrence, 1995). However, these cost-benefit analyses did not explicitly take into account one potential cost of DRLs-an increase in discomfort glare.

Discomfort glare, while not included in the formal cost-benefit analyses, has been of major concern in relation to setting various parameters of DRLs, including the maximum luminous intensity (e.g., Hörberg and Rumar, 1975; Kirkpatrick, Baker, and Heasly, 1987; Kirkpatrick and Marshall, 1989) and the maximum mounting height (Sivak, Flannagan, and Aoki, 1995).

One parameter of DRLs that has not yet received formal evaluation is the lateral separation of the lamps. There is anecdotal evidence that narrowly spaced lamps lead to more discomfort glare than widely spaced lamps of equal light output. The present study examined the hypothesis that while narrowly spaced lamps create somewhat more discomfort, this "cost" is more than compensated for by an increase in "benefits" consisting of a major increase in conspicuity. In addition to varying lamp separation, we also varied lamp intensity, in order to scale the effects of lamp separation against the effects of lamp intensity (an intuitively understandable variable) on both conspicuity and discomfort glare. 


\section{METHOD}

\section{Experimental setup}

Schematic diagrams of the experimental setup and the subject's view are shown in Figures 1 and 2. The subjects were seated in a stationary late-model sedan. Directly in front of the subject was another car. (It served to shield two experimenters from the subject's view.) To the left of that car there was a rack with six headlamps; to the right of that car there was a single headlamp mounted on a tripod. This lamp will be referred to as the comparison lamp. Both the rack and the tripod were at a longitudinal distance of $20 \mathrm{~m}$ from the subject. The center of the rack was offset $3.37 \mathrm{~m}$ to the left of straight ahead to correspond to the standard geometrical relation in the U.S. between the position of a driver and the center of an oncoming vehicle in an adjacent lane (Sivak, Flannagan, Budnik, Flannagan, and Kojima, 1997). The center of the lamp on the tripod was offset $3.37 \mathrm{~m}$ to the right of straight ahead. Consequently, the center of the rack and the center of the tripod were $20.3 \mathrm{~m}$ from the subject's eye point, and at $9.6^{\circ}$ of visual angle to the left and right, respectively, from straight ahead. The centers of all seven lamps were $0.62 \mathrm{~m}$ above the ground, to correspond to the average mounting height of headlamps on U.S. cars (Sivak et al., 1997).

The seven lamps were of the same construction-high-beam, tungsten halogen sealed beams, H4701 (92 $\mathrm{mm}$ by $150 \mathrm{~mm}$ ). Each of the six lamps on the rack were individually adjusted in such a way that, at $12.8 \mathrm{~V}$, they each directed 7,000 cd towards the position of the eyes of the subject. The lamp on the tripod was adjusted so that, at $14.7 \mathrm{~V}$ (the maximum voltage available), it directed $36,820 \mathrm{~cd}$ towards the subject's eyes. In order to measure the light output of the lamps without interference from high daytime light levels, the adjustments and photometry were made during the nighttime; the readings were made without taking into account the transmittance losses due to the windshield. 


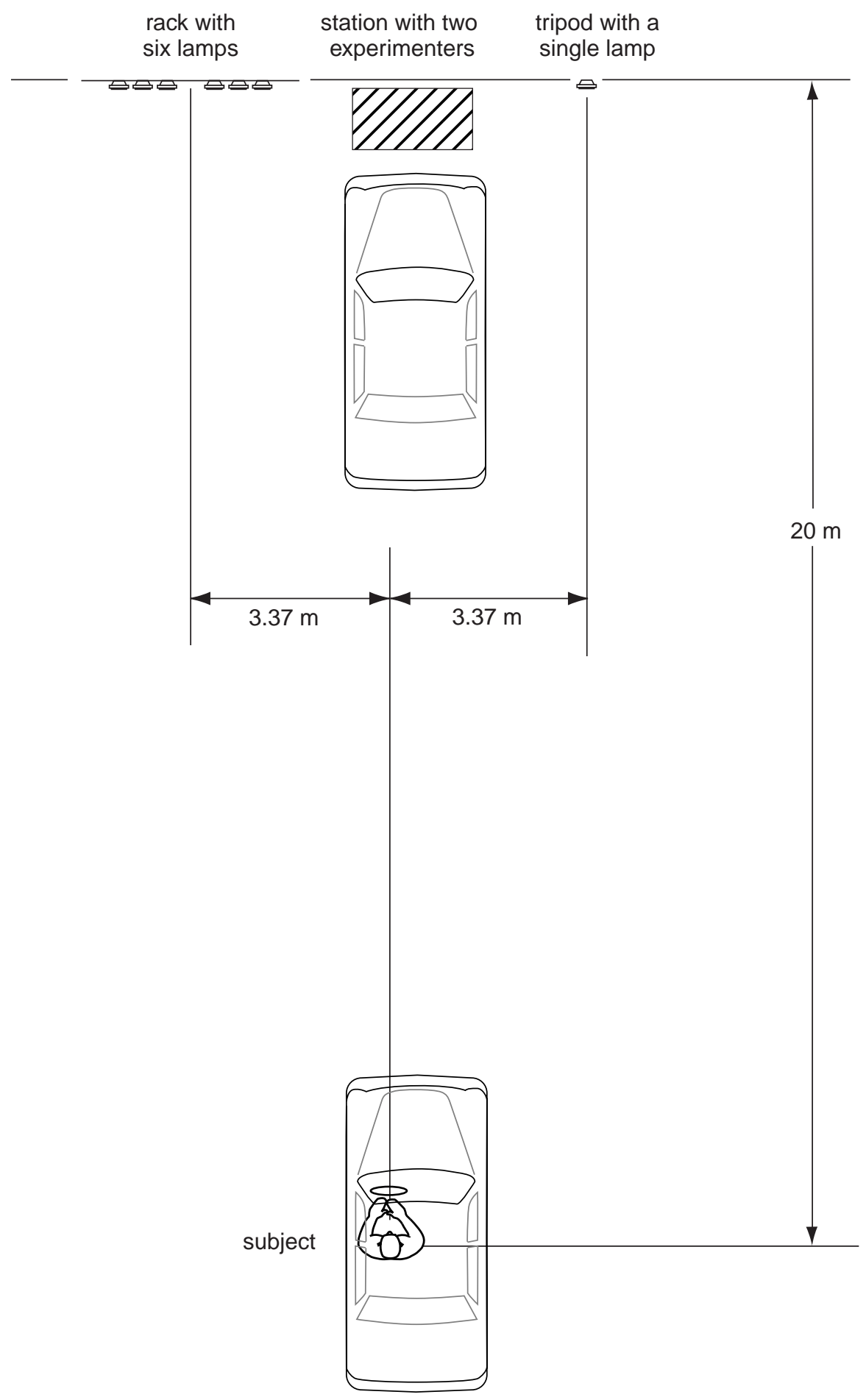

Figure 1. A schematic of the experimental setup. 


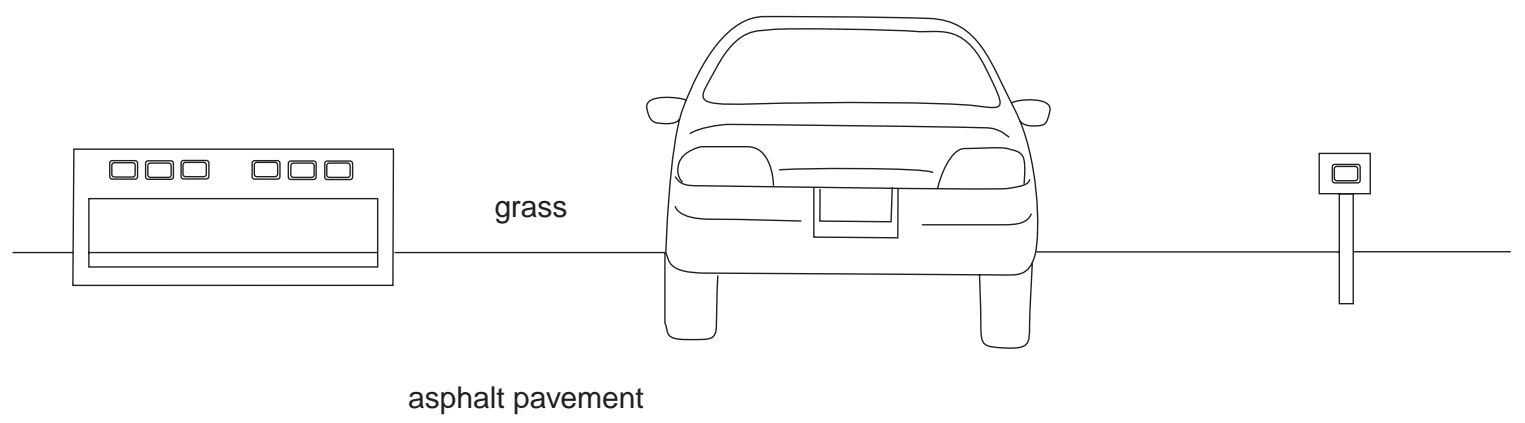

Figure 2. A schematic of the subject's view.

\section{Tasks}

Each subject performed two tasks: rating discomfort glare from a pair of lamps that were energized on the rack to the left of straight ahead, and evaluating the conspicuity of the same lamps.

Discomfort glare. To rate discomfort glare, subjects were asked to use the de Boer response scale. This scale has been used often to evaluate glare in night driving situations (Bhise, Swigart, and Farber, 1975; de Boer, 1967). It is a 9-point scale with qualifiers only for the odd points as follows: 1 (unbearable), 2, 3 (disturbing), 4, 5 (just acceptable), 6, 7 (satisfactory), 8, 9 (just noticeable). A copy of the de Boer scale was given to each subject to be referred to throughout the discomfort-glare session as needed.

Conspicuity. To evaluate the conspicuity of the lamps, subjects were asked to adjust the brightness of the comparison lamp on the right so that it was as noticeable as the pair of lamps on the left. The brightness adjustment was made by turning a knob that controlled the voltage applied to the lamp on the right (from 0 to $14.7 \mathrm{~V}$ ). This method is analogous to the one used by Howett (1979) to evaluate conspicuity of flashing lights.

\section{Stimuli}

Nine stimuli were used in both the glare and conspicuity portions of the study. These stimuli were obtained by the orthogonal combination of three levels of luminous intensity directed to the subject's eyes from the two lamps $(14,000,3,500$, and $875 \mathrm{~cd})$, and three levels of lamp separation (1.05, 0.65, and $0.25 \mathrm{~m}$ - edge to edge).

The two lower levels of intensity were achieved by placing neutral density filters in front of the lamps. (These filters had transmittance of $25 \%$ and $6.25 \%$, respectively.) No 
filters were used to achieve the highest intensity level. When filters were used, they covered all six of the lamps on the rack so that the subject was not given an advanced cue concerning which pair of lamps would be energized during the upcoming trial.

The narrowest lamp-separation condition used the inner two lamps, the widest condition used the outer two lamps, and the intermediate condition used the remaining two lamps. This arrangement assured that for each condition the center of the two energized lamps was in the same location.

The lamps were connected to a switch box that controlled which lamps were energized on each trial. A timer connected to the switch box allowed timed presentations of the stimuli in the discomfort-glare portion of the study.

\section{Ambient conditions}

The study was run only on bright, sunny days. The ambient illumination was evaluated by measuring vertical lux in front of the subject's windshield three times during each session: at the beginning of the session, between the two blocks of trials, and at the end of the session. The readings averaged 13,470 lux, with a minimum of 10,200 lux and a maximum of 18,400 lux.

\section{Subjects}

Sixteen paid subjects participated in the study. There were 8 younger subjects (ranging from 20 to 31 years old, with a mean of 26.6) and 8 older subjects (ranging from 65 to 76 years old, with a mean of 69.5). Each age group included 4 males and 4 females. All subjects were licensed drivers.

\section{Procedure}

Subjects were tested individually. Each subject performed both tasks (discomfortglare rating and conspicuity evaluation). The trials were run in 2 blocks of 36 trials each ( 3 lamp separations times 3 lamp intensities times 4 replications). One block of trials was devoted to rating discomfort glare, and one to evaluating conspicuity. The orders of the two blocks were balanced across age and sex, and the 36 trials within each block were randomized. Each block of trials was preceded by 4 practice trials. The practice trials involved the four combinations of the widest and narrowest lamp separations paired with the lowest and highest lamp intensity. The study took about 75 minutes to complete. 
Discomfort glare. The instructions for this block of trials specified that "in this part we are concerned with discomfort glare from the daytime use of vehicle headlamps.... Your task will be to rate the amount of discomfort you experience from these lamps." In this portion of the study, only two of the six lamps on the left were energized on each trail; the single lamp on the right was off throughout. On each trial, the lamps were on for 2 seconds.

Conspicuity. The instructions for this block of trials specified that "in this part we are concerned with the noticeability, or attention-getting properties, of lamps designed to mark the presence of vehicles during the day....Your task will be to adjust the brightness of the single lamp on the right, so that it is equally noticeable as the two lamps on the left combined." One half of the conspicuity trials started with the voltage set at $0 \mathrm{~V}$, and thus the initial brightness adjustment of the comparison lamp was upwards. The other half of the trials started with the voltage set at the maximum $(14.7 \mathrm{~V})$, and thus the initial brightness adjustment was made downwards. Once the subjects began the adjustment (upwards or downwards), they were free to move in either direction in order to locate the equally noticeable setting. In this portion of the study, all three lamps remained energized until the subject was satisfied with the match.

Subjects were instructed to look at the rear of the car parked directly ahead throughout the entire experiment. Furthermore, they were asked to look down at their lap in between trials while the experimenters adjusted the filters over the lamps as needed.

\section{Conversion of voltage to luminous intensity for the conspicuity trials}

The raw data for the conspicuity trials were in terms of voltage for the comparison lamp on the right that yielded equal conspicuity between that lamp and the two lamps on the left. In order to convert the voltage readings to luminous intensity, illuminance readings in vertical lux at the subject's eye point were taken during the nighttime for voltages ranging from 4 to $14.5 \mathrm{~V}$. (These readings did not take into account light losses due to the presence of the windshield.) Figure 3 presents the obtained relationship between voltage and intensity. This relationship was well described by the following empirical function:

$$
\text { illuminance }=-0.001 * \text { voltage }^{4}+0.072 * \text { voltage }^{3}-0.506 * \text { voltage }^{2}+1.180 * \text { voltage }-0.668
$$

The illuminance readings derived from this equation were converted to luminous intensities by multiplying the lux values by 412.09 (the square of the distance, in meters, between the lamp and the subject's eye point.) 


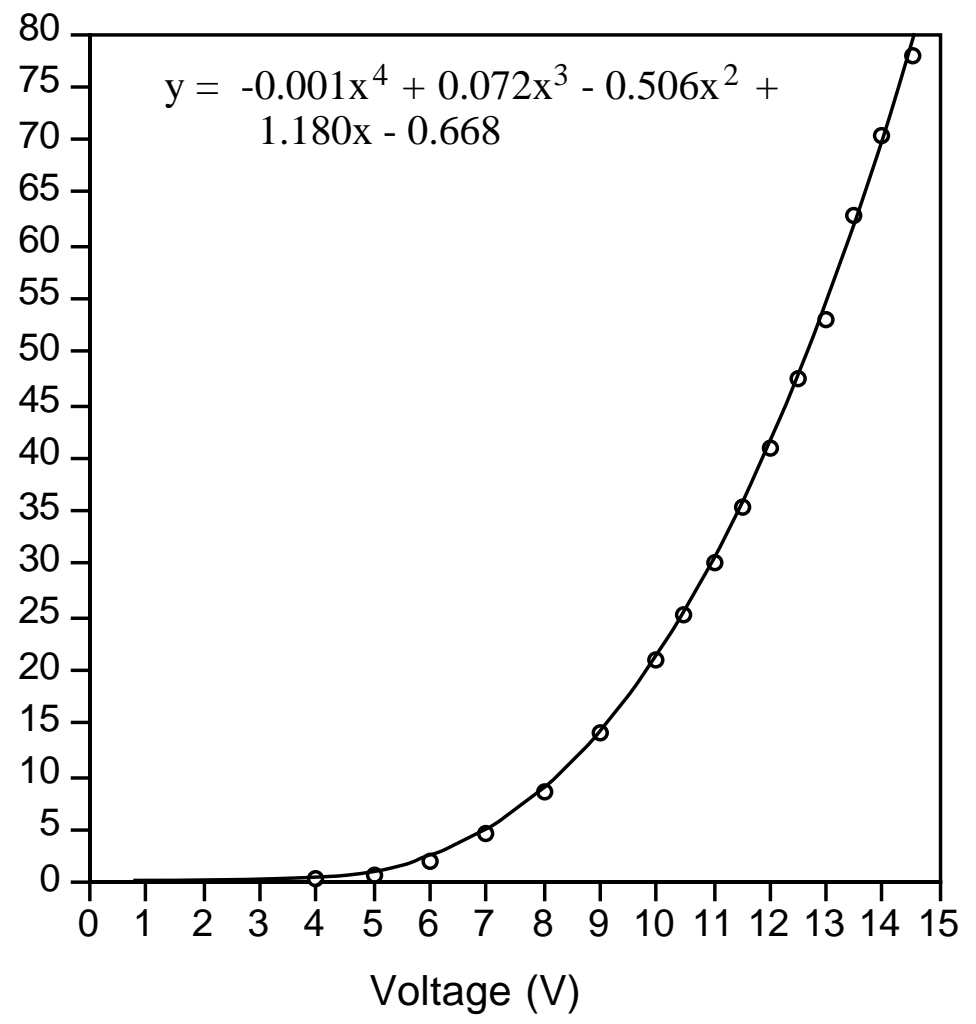

Figure 3. Relationship between voltage and illuminance from the comparison lamp. 


\section{RESULTS AND DISCUSSION}

\section{Discomfort glare}

An analysis of variance was performed on the de Boer ratings of discomfort. The independent variables were: combined intensity of the two lamps $(14,000,3,500$, or $875 \mathrm{~cd})$, lamp separation (1.05, 0.65 , or $0.25 \mathrm{~m}$ ), subject age group (younger or older), subject sex (male or female), and order of tasks (discomfort glare first or conspicuity first).

The main result of this analysis is that the only statistically significant effect was the effect of lamp intensity, $F(2,24)=92.9, p<.0001$. (For this and all other tests in this study involving within-subject independent variables with more than two levels, the GreenhouseGeiser adjustment was used.) As expected, subjects' glare ratings were highly sensitive to lamp intensity: the higher the intensity, the greater was the discomfort. The mean glare ratings for the three levels of intensity are shown in Table 1.

Although there was a tendency for narrower separations to lead to greater discomfort, the effect failed to reach statistical significance, $F(2,24)=3.0, p=.08$. The mean glare ratings for the three levels of lamp separation are shown in Table 2. The effects of age, sex, and order of tasks were not statistically significant.

Table 1

The effect of lamp intensity on de Boer ratings of discomfort glare.

(Lower de Boer units indicate more discomfort.)

\begin{tabular}{|c|c|}
\hline Combined intensity of two lamps (cd) & Discomfort glare (de Boer units) \\
\hline \hline 14,000 & 3.9 \\
\hline 3,500 & 6.2 \\
\hline 875 & 7.9 \\
\hline
\end{tabular}

Table 2

The effect of lamp separation on de Boer ratings of discomfort glare.

(Lower de Boer units indicate more discomfort.)

\begin{tabular}{|c|c|}
\hline Lamp separation $(\mathrm{m})$ & Discomfort glare (de Boer units) \\
\hline \hline 0.25 & 5.8 \\
\hline 0.65 & 6.0 \\
\hline 1.05 & 6.1 \\
\hline
\end{tabular}




\section{Conspicuity}

An analysis of variance was performed on the settings of the intensity level for the comparison lamp. The independent variables were combined intensity of the two lamps on the left $(14,000,3,500$, or $875 \mathrm{~cd})$, lamp separation $(1.05,0.65$, or $0.25 \mathrm{~m})$, subject age group (younger or older), subject sex (male or female), order of tasks (discomfort glare first or conspicuity first), and direction of initial brightness adjustment (upwards or downwards).

The effect of lamp intensity was statistically significant, $F(2,24)=77.8, p<0.0001$. As expected, subjects rated more intense lamps as being more noticeable. The mean conspicuity ratings for the three levels of lamp intensity are shown in Table 3.

Note that the intensity of the comparison lamp needed to match the pair of lamps on the left was always higher than the combined intensity of that pair. This was especially true for the lower intensities. This effect may be due to a combination of substantive and technical factors. On the substantive side, the fact that the pair of lamps on the left have, in combination, twice the area of the single comparison lamp may make them truly more conspicuous than the comparison lamp for a given total intensity. On the technical side, it is a common finding that people in experiments like this one, where stimulus and response variables are on the same scale, tend to use a smaller range for the variable that is under their control (the intensity of the comparison lamp) than for the variable that is not under their control (the combined intensity of the pair of lamps). The reasons for this tendency are not well understood. However, the actual mechanisms responsible for the conspicuity values are not of direct interest in this study. Our only purpose is to use the intensity value set by the subjects to make comparisons across the combinations of intensity and separation of the pair of lamps on the left, as we will demonstrate in the next section.

Table 3

The effect of lamp intensity on conspicuity.

\begin{tabular}{|c|c|}
\hline Combined intensity of two lamps (cd) & Conspicuity (intensity of the comparison lamp (cd)) \\
\hline \hline 14,000 & 15,410 \\
\hline 3,500 & 6,495 \\
\hline 875 & 2,973 \\
\hline
\end{tabular}


The effect of lamp separation was also statistically significant, $F(2,24)=9.5, p=$ 0.001 , with less separated lamps being judged as more noticeable. The mean conspicuity ratings for the three levels of lamp separation are shown in Table 4. The effects of age, sex, order of tasks, and direction of initial brightness adjustment were not statistically significant.

Table 4

The effect of lamp separation on conspicuity.

\begin{tabular}{|c|c|}
\hline Lamp separation $(\mathrm{m})$ & Conspicuity (intensity of the comparison lamp (cd)) \\
\hline \hline 0.25 & 9,002 \\
\hline 0.65 & 8,512 \\
\hline 1.05 & 7,364 \\
\hline
\end{tabular}




\section{Glare: tradeoff between separation and intensity}

As reported above, an analysis of variance showed that the effect of lamp intensity on discomfort glare was statistically significant. Furthermore, although the effect of lamp separation failed to reach statistical significance, there was a tendency for narrower separations to lead to more glare.

Previous research has shown that discomfort glare is a linear function of the logarithm of illuminance (e.g., Schmidt-Clausen and Bindels, 1974; Sivak, Flannagan, Traube, and Kojima, 1998). Indeed, that proved to be the case in this study as well (see Figure 4). Furthermore, the relationship between the logarithm of lamp separation and discomfort glare was also well described by a linear function (see Figure 5). (The abovereported analysis of variance indicated that the effect of separation on discomfort was not statistically significant. Consequently, the relationship in Figure 5 should not be taken too seriously. Nevertheless, the relationship shown there can be considered a provisional estimate about how separation affects discomfort.)

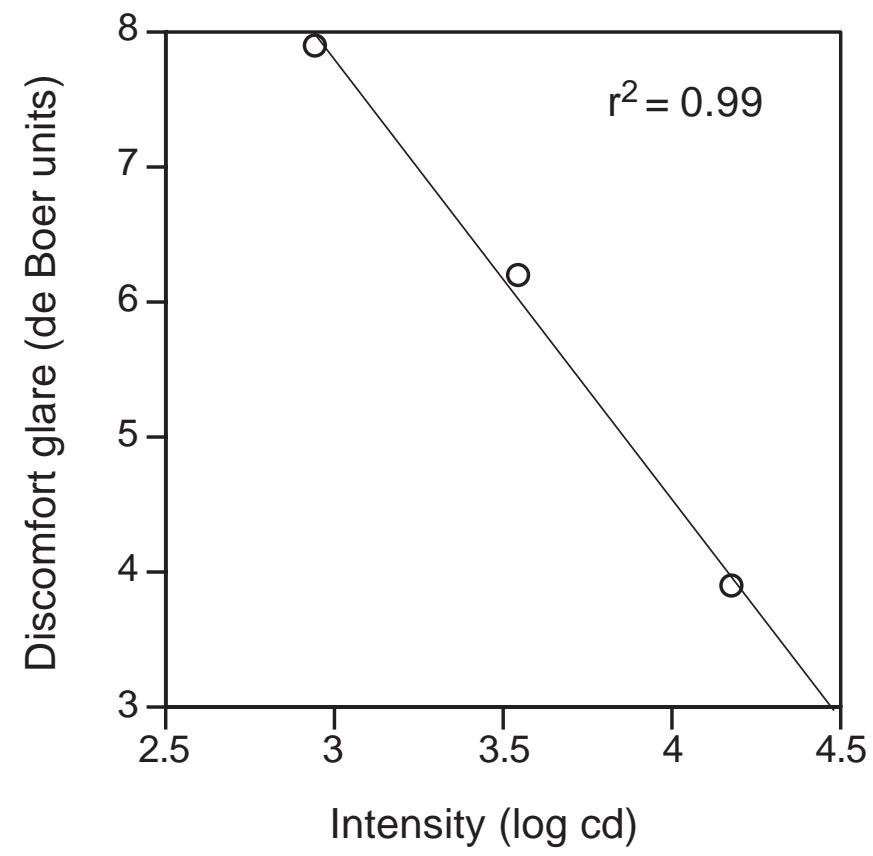

Figure 4. The relationship between log intensity and discomfort glare. (Lower de Boer units indicate more discomfort.) 


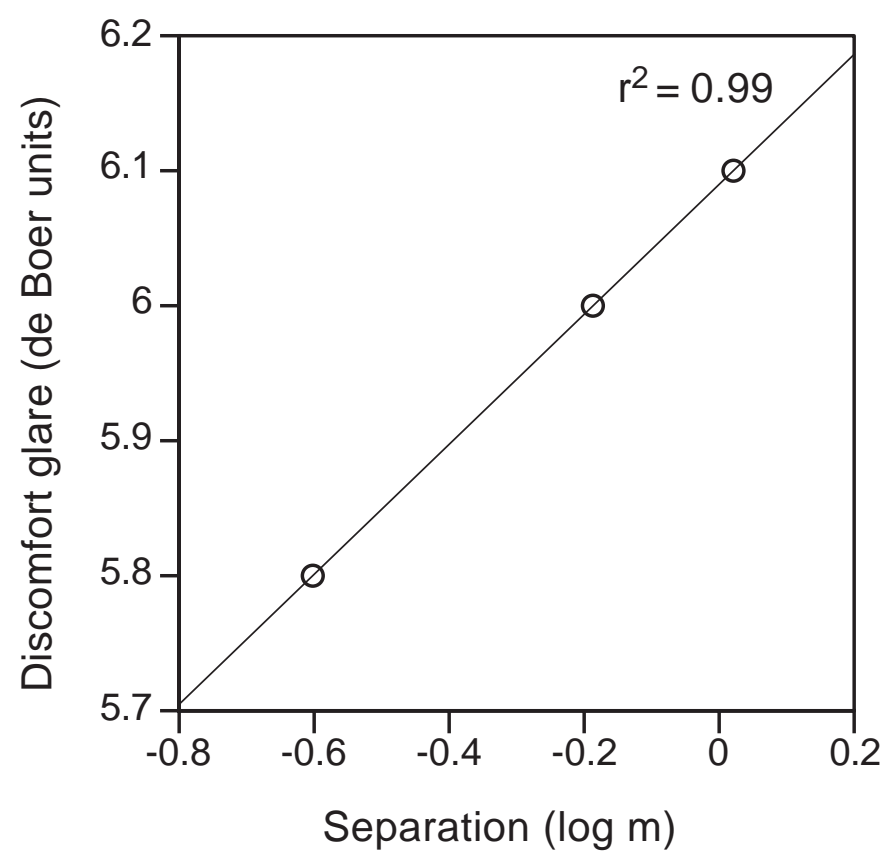

Figure 5. The relationship between log separation and discomfort glare. (Lower de Boer units indicate more discomfort.)

A multiple regression of discomfort glare was performed, using the logarithms of lamp intensity and lamp separation as predictors. The goal of this analysis was the derivation of the regression coefficients for the two predictors, in order to estimate the relative importance of the two predictors. This analysis indicates that the best-fitting plane accounted for $99.2 \%$ of the variance in discomfort glare. The best-fitting plane had the following equation:

$$
\text { discomfort glare }=17.91-3.33 * \log (\text { intensity })+0.49 * \log (\text { separation })
$$

where discomfort glare is in de Boer units, intensity in candela, and separation in meters.

The ratio of the two respective coefficients (3.33 and 0.49$)$ is 6.80 . This ratio indicates that the increase in discomfort glare that might be caused by a certain reduction in separation can be compensated for by a reduction in intensity that is (in log terms) 6.80 times smaller. For example, let us consider a situation with a lamp intensity of 5,000 cd and a lamp separation of $0.5 \mathrm{~m}$. The above calculations indicate that the increase in glare due to a decrease to 0.5 times the original separation (from $0.5 \mathrm{~m}$ to $0.25 \mathrm{~m}$ ) can be counteracted by a decrease to 0.9031 times the original intensity (from $5,000 \mathrm{~cd}$ to $4,516 \mathrm{~cd}$ ). (The ratio of the $\log$ arithms of the changes - $\log 0.5 / \log 0.9031$ - is equal to 6.80.) 


\section{Conspicuity: tradeoff between separation and intensity}

As reported above, an analysis of variance showed that the effects of both lamp intensity and lamp separation on conspicuity were statistically significant. Regression analyses showed that for conspicuity the linear fits of the logarithms of intensity and separation, while not as good as for discomfort glare, were still acceptable (see Figures 6 and 7).

Various alternatives to the analyses shown in Figure 6 and 7 could be considered. It could be argued that conspicuity should also be log transformed, so that it would have the same units as the intensity of the pair of lamps on the left (i.e., log cd). However, our present purpose is not to explore the details of the relationship between the intensity of the comparison lamp and the combined intensities of the pair of lamps. The purpose is only to use the intensity of the comparison lamp to equate conspicuity of the pair of lamps across different intensities and separations. For that limited purpose, and with modest ambitions for precision, the quality of the fits in Figures 6 and 7 seems adequate.

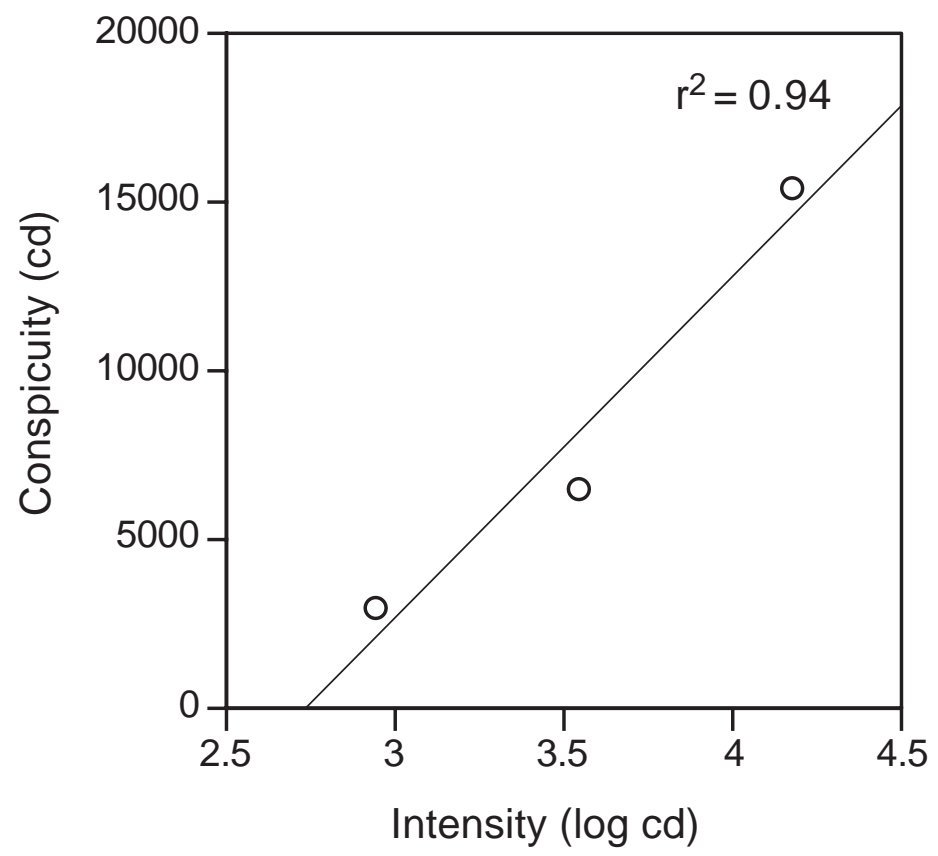

Figure 6. The relationship between log intensity and conspicuity. 


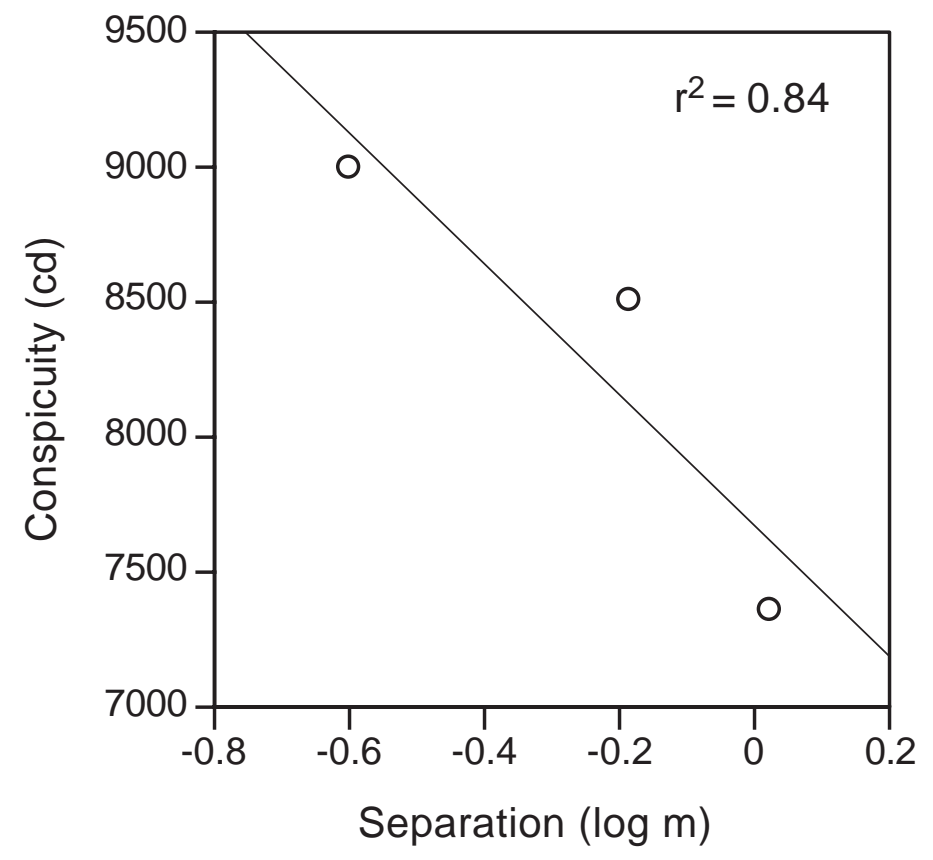

Figure 7. The relationship between log separation and conspicuity.

A multiple regression of conspicuity on the two predictors accounted for $93.2 \%$ of the variance. The best-fitting plane had the following equation:

$$
\text { conspicuity }=-28,933+10,329 * \log (\text { intensity })-2,424 * \log \text { (separation) }
$$

where conspicuity is in candela (of the comparison lamp), intensity in candela, and separation in meters.

The ratio of the two respective coefficients $(10,329$ and 2,424) is 4.26 . This ratio indicates that the decrease in conspicuity caused by a certain increase in separation can be compensated for by an increase in intensity that is (in log terms) 4.26 times smaller. For example, let us, again, consider the situation with a lamp intensity of 5,000 cd and a lamp separation of $0.5 \mathrm{~m}$. The above calculations indicate that the decrease in conspicuity due to an increase to 1.5 times the original separation (from $0.5 \mathrm{~m}$ to $0.75 \mathrm{~m}$ ) can be counteracted by an increase to 1.0998 times the original intensity (from 5,000 $\mathrm{cd}$ to 5,499 cd). (The ratio of the logarithms of the changes- $\log 1.5 / \log 1.0998$-is equal to 4.26.) 


\section{Net effect of changes in lamp separation and lamp intensity}

The ratio of the coefficients for log intensity and log separation from the multiple regression of discomfort glare (6.80) was greater than the corresponding ratio from the multiple regression of conspicuity (4.26). This fact implies that, even if lamp intensity is reduced to compensate for the increase in discomfort glare due to a reduction in lamp separation, there will still be a net improvement in terms of conspicuity. Let us, again, consider the condition with a lamp intensity of 5,000 cd and a lamp separation of $0.5 \mathrm{~m}$. As indicated above, the increase in discomfort glare due to a 50\% reduction in separation (to $0.25 \mathrm{~m}$ ) can be compensated for by a $9.68 \%$ decrease in intensity (to $4,516 \mathrm{~cd}$ ). In other words, this new condition (separation of $0.25 \mathrm{~m}$ and intensity of 4,516 cd) will result in the same level of discomfort glare as the original condition (separation of $0.5 \mathrm{~m}$ and intensity of $5,000 \mathrm{~cd}$ ). However, the new condition will result in greater conspicuity than the original condition. Specifically, using the regression equation from page 14 , the conspicuity of the new condition is predicted to be equivalent to the comparison lamp at an intensity of $10,276 \mathrm{~cd}$, as compared to $10,003 \mathrm{~cd}$ for the original condition.

Alternatively, the increase in conspicuity due to a decrease in lamp separation could allow a decrease in lamp intensity with no loss in conspicuity, thus allowing an improvement in terms of discomfort glare. Let us consider, for the final time, the condition with a lamp intensity of 5,000 cd and a lamp separation of $0.5 \mathrm{~m}$. The increase in lamp conspicuity due to a $50 \%$ reduction in separation (to $0.25 \mathrm{~m}$ ) would allow a $15.02 \%$ decrease in intensity (to $4,249 \mathrm{~cd}$ ) with no net change in conspicuity. However, the new condition would result in slightly less discomfort glare than the original condition. Specifically, using the regression equation from page 12, the de Boer rating of the new condition is predicted to be 5.5 , as compared to 5.4 for the original condition.

The precision of the calculations in this section depends on the quality of the loglinear fits in Figures 4 through 7. While, these fits were very good for discomfort glare (Figures 4 and 5), they were only acceptable for conspicuity (see Figures 6 and 7). Consequently, the calculated values should be viewed only as illustrations of general trends. Nevertheless, the message that should be taken from this section (and from the regression analyses) is consistent with that from the analyses of variance: Lamp intensity had a strong influence on both conspicuity and discomfort glare. On the other hand, the effect of lamp separation was stronger on conspicuity than on discomfort glare. Consequently, when combining the conspicuity and discomfort-glare concerns, there is a net benefit in using narrowly separated lamps. 


\section{Optimal separation of daytime running lights}

The results of the present study indicate that, when considering the combined effects on conspicuity and glare, there is a net benefit in using narrowly separated daytime running lights. This finding applies to the range tested (between 1.05 and $0.25 \mathrm{~m}$ ). However, whether this finding can be extrapolated outside of the range tested remains to be seen.

This study was performed under bright, sunny conditions. Although there is no reason to expect that the tradeoff of the effects of lamp separation and intensity on discomfort glare and conspicuity would be different for other levels of ambient illumination (such as those during cloudy days), that possibility should be tested in future studies.

In addition to conspicuity and glare, there are other considerations related to the spacing of daytime running lights that may be important. One consideration is that lamps that are positioned as much outboard as possible might provide additional information about the width of the vehicle, and thus might be helpful in meeting situations. However, it is likely that this marking function of lamps is more important during the nighttime than during the daytime. Another consideration is that during the nighttime narrowly separated low-beam headlamps are perceived as being further away than widely separated headlamps (Flannagan, Sivak, Aoki, Traube, and Harrison, 1995). Again, however, it is unclear whether this finding has any applicability for daytime conditions. 


\section{SUMMARY}

This study evaluated the influences of lamp separation and lamp intensity on the effectiveness of daytime running lights. Subjects performed two tasks. They rated discomfort glare from a pair of lamps, and evaluated the conspicuity of the same lamps. The same nine stimuli were used in both the glare and conspicuity portions of the study. These nine stimuli were obtained by the orthogonal combination of three levels of luminous intensity directed towards the subject's eyes from the two lamps $(14,000,3,500$, and $875 \mathrm{~cd}$ ), and three levels of lamp separation (1.05, 0.65, and $0.25 \mathrm{~m}$-edge to edge). The study was performed outdoors, on bright, sunny days. The viewing distance was 20 m.

As expected, lamp intensity had strong effects on both discomfort glare and conspicuity. On the other hand, in the case of lamp separation, there was more evidence for an effect on conspicuity (narrowly separated lamps being more noticeable) than on discomfort glare (a statistically nonsignificant trend for narrowly separated lamps to be only slightly more discomforting). Consequently, if the possible increase in discomfort from narrowly separated lamps is counteracted by a slight reduction in intensity, there is still a net benefit for narrowly separated lamps in terms of conspicuity. Conversely, narrowly separated lamps that are as noticeable as widely separated lamps of higher intensity would be less glaring. The present findings imply that there is a small net benefit in using narrowly separated daytime running lights. 


\section{REFERENCES}

Allen, M.J. and Clark, J.R. (1964). Automobile running lights-a research report. American Journal of Optometry and Archives of American Academy of Optometry, Monograph No. 331.

Bhise, V.D., Swigart, T.F., and Farber, E.I. (1975). Development of a headlamp dimming request prediction model. In R.N. Hale, R.A. McKnight, and J.R. Moss (Eds.) Human factors in our expanding technology (Proceedings of the 19th annual meeting of the Human Factors Society) (pp. 284-295). Santa Monica, CA: The Human Factors Society.

CIE (Commission Internationale de l'Eclairage). (1993). Daytime running lights (Publication No. CIE 104). Vienna, Austria: Author.

de Boer, J.B. (1967). Visual perception in road traffic and the field of vision of the motorist. In J.B. de Boer (Ed.), Public lighting. Eindhoven, The Netherlands: Philips Technical Library.

Elvik, R. (1996). A meta-analysis of studies concerning the safety effects of daytime running lights on cars. Accident Analysis \& Prevention, 28, 685-694.

Flannagan, M.J., Sivak, M., Aoki, M., Traube, E.C., and Harrison, A.K. (1995). Effects of the lateral position of low-beam headlamps on the perceived distance of vehicles (Report No. UMTRI-95-21). Ann Arbor: The University of Michigan Transportation Research Institute.

Helmers, G. (1988). Daytime running lights: A potent traffic safety measure? (Report No.333A). Linköping: VTI Swedish National Traffic Safety Institute.

Hörberg, U. and Rumar, K. (1975). Running lights conspicuity and glare (Report No. 178). Uppsala, Sweden: University of Uppsala, Department of Psychology.

Howett, G.L. (1979). Some psychophysical tests of the conspicuities of emergency vehicle warning lights (NBS Special Publication 480-36). Washington, D.C.: National Bureau of Standards.

Kirkpatrick, M., Baker, C.C., and Heasly, C.C. (1987). A study of daytime running light design factors (Report No. DOT HS 807 193). Washington, D.C.: National Highway Traffic Safety Administration.

Kirkpatrick, M. and Marshall, R.K. (1989). Evaluation of glare from daytime running lights (Report No. DOT HS 807 502). Washington, D.C.: National Highway Traffic Safety Administration. 
Koornstra, M., Bijleveld, F., and Hagenzieker, M. (1997). The safety effects of daytime running lights (Report No. R-97-36). Leidschendam, The Netherlands: SWOV Institute for Road Safety.

Lawrence, E. (1995). Preliminary economic evaluation of the costs and benefits of the daytime running lights (Report No. TP 12517 E). Ottawa: Transport Canada.

Schmidt-Clausen, H.J. and Bindels, J.T.H. (1974). Assessment of discomfort glare in motor vehicle lighting. Lighting Research and Technology, 6, 79-88.

Sivak, M., Flannagan, M.J., and Aoki, M. (1995). Glare and mounting height of high beams used as daytime running lamps (Report No. UMTRI-95-40). Ann Arbor: The University of Michigan Transportation Research Institute.

Sivak, M., Flannagan, M.J., Traube, E.C., and Kojima, S. (1998). The influence of stimulus duration on discomfort glare for persons with and without visual correction (Report No. UMTRI-97-23). Ann Arbor: The University of Michigan Transportation Research Institute.

Theeuwes, J. and Riemersma, J.B.J. (1995). Daytime running lights as a vehicle collision countermeasure: The Swedish evidence reconsidered. Accident Analysis \& Prevention, 27, 633-642. 